\title{
Journal of \\ Testing and Evaluation
}

Alvaro García, ${ }^{1,3}$ Jose Norambuena-Contreras, ${ }^{4}$ Moises Bueno, ${ }^{2}$ and Manfred N. Partt ${ }^{2,5}$

DOI: $10.1520 / J T E 20130197$

Influence of Steel Wool Fibers on

the Mechanical, Termal, and

Healing Properties of Dense

Asphalt Concrete

VOL. 42 / NO. 5 / SEPTEMBER 2014

Copyright by ASTM Int'l (all rights reserved); Wed Jul 30 06:02:07 EDT 2014 
Manuscript received August 12, 2013; accepted for publication January 8, 2014; published online July 1, 2014.

1 Empa, Swiss Federal Laboratories for Materials Science and Technology, $\mathrm{CH}-8600$ Duebendorf, Switzerland (Corresponding author),

e-mail: alvaro.garcia@empa.ch

2 Empa, Swiss Federal Laboratories for Materials Science and Technology, $\mathrm{CH}-8600$ Duebendorf, Switzerland.

3 Division of Infrastructure and Geomatics, Faculty of Engineering, Univ. of Nottingham, University Park, NG7 2RD, UK.

4 Department of Civil and Environmental Engineering, University of Bío-Bío, Concepción, Chile, e-mail author contact: norambuenaje@gmail.com

${ }^{5}$ School of Architecture and the Build Environment, KTH Stockholm, Highway and Railway Engineering, 10044 Stockholm, Sweden.
Alvaro García, ${ }^{1,3}$ Jose Norambuena-Contreras, ${ }^{4}$ Moises Bueno, ${ }^{2}$ and Manfred N. Partt ${ }^{2,5}$

\section{Influence of Steel Wool Fibers on the Mechanical, Termal, and Healing Properties of Dense Asphalt Concrete}

\section{Reference}

García, Alvaro, Norambuena-Contreras, Jose, Bueno, Moises, and Partl, Manfred N., "Influence of Steel Wool Fibers on the Mechanical, Termal, and Healing Properties of Dense Asphalt Concrete," Journal of Testing and Evaluation, Vol. 42, No. 5, 2014, pp. 1-12, doi:10.1520/JTE20130197. ISSN 0090-3973

\section{ABSTRACT}

This paper summarizes the main results of experimental research on the induction healing of dense asphalt concrete with steel wool fibers. Different physical properties of dense asphalt concrete, as the steel wool fibers distribution, mechanical properties, thermal conductivity, and healing via induction heating have been analysed. The main results show that short and thick fibers disperse very well in the mixture, while long and thin fibers produce clusters. It was also observed that fibers can be damaged during the mixing and compaction processes. In addition, it was found that steel wool fibers do not significantly improve the mechanical properties and damage resistance of dense asphalt concrete. Moreover, steel wool fibers slightly increase the thermal conductivity of dense asphalt concrete. Furthermore, the temperature reached due to induction heating increases with the number of fibers in the mixture and with their diameter. Finally, it was found that dense asphalt concrete heals through the increase of temperature and that the type and diameter of fibers do not influence the healing properties of dense asphalt concrete.

\section{Keywords}

asphalt concrete, steel wool fibers, mechanical properties, thermal properties

\section{Introduction}

Asphalt concrete is a self-healing material. When the temperature is above a certain threshold, cracks start closing by themselves. Bitumen starts behaving like a Newtonian fluid at temperatures ranging from 30 to $70^{\circ} \mathrm{C}$, depending on the type of bitumen [1]. Above this temperature, bitumen may start flowing through any possible crack open in the pavement, in a sort of capillary flow [2]. 
This may happen naturally when the temperature is high enough; for example during the summer, although it can be also promoted artificially by induction heating [3] or by microwave heating [4].

Induction heating consists in adding electrically conductive fibers into the asphalt mixture (see Fig. 1). Then, with the help of an induction heating device, it is possible to heat the fibers locally, and for this reason, heat the pavement and heal the cracks. In Ref. [5], it was discovered that a very small volume of fibers, more than $0 \%$, serves to increase the temperature of asphalt concrete via induction heating; however, there is a maximum volume of fibers, $6 \%-7 \%$, above which the temperature does not increase any more. Additionally, in Ref. [6], it is shown that the increase of temperature in asphalt concrete due to induction heating depends mainly on the radius of the fibers more than on their volume in the mixture. Moreover, more parameters which have great influence on the heating rates are the frequency and intensity of the alternating magnetic field used. Besides, in Ref. [7], it can be seen that the steel wool fibers may deteriorate the mechanical properties of the mixture in case fibers are not well dispersed.

Furthermore, it has been reported that fibers can be mixed in asphalt concrete for improving its strength and fatigue properties, while increasing its ductility [8]. Moreover, fibers can change the viscoelasticity [9], dynamic modulus [10], creep compliance, rutting [11], and freeze-thaw resistance [12] of asphalt concrete. In addition, when the fibers have high tensile strength relative to the binder, they may improve the cohesive and tensile strength of asphalt mixtures [13]. In Ref. [7], it is shown that a bad distribution of steel wool fibers can lead to a higher porosity in the asphalt concrete, which may reduce its durability. In addition, fibers in asphalt concrete may have other applications, such as improving its electrical conductivity [14]: if an increasing mass of fibers is added to the mixture, there is a point when these percolate, creating an electrically conductive path thought the material.

This paper has been prepared as the compilation of stages in a research about induction-healing of dense asphalt concrete. To reach the objectives, electrically conductive steel wool fibers have been added to the asphaltic mixture. These fibers may influence the mechanical properties of dense asphalt concrete. Additionally, it is not clear which diameter and which amount of fibers are more appropriate to heat dense asphalt concrete via induction heating. Furthermore, the factors influencing induction-healing of dense asphalt concrete have not been yet quantified. With this purpose, 25 different asphalt concrete mixtures, with the same aggregates distribution and amounts of bitumen, but with 2 different average lengths of fibers, 4 different fiber contents, and 4 different diameters of steel wool have been prepared and their mechanical, heating, and healing properties have been analysed.

\section{Experimental Method}

\section{MATERIALS}

A dense asphalt concrete mixture was used in this research. The dense graded aggregates distribution is shown in Table 1. The aggregates consisted of crushed basaltic material (size between 2 and $11 \mathrm{~mm}$ and density $2770 \mathrm{~kg} / \mathrm{m}^{3}$ ), crushed sand (size between 0.063 and $2 \mathrm{~mm}$ and density $2688 \mathrm{~kg} / \mathrm{m}^{3}$ ), and filler (size $<0.063 \mathrm{~mm}$ and density $2638 \mathrm{~kg} / \mathrm{m}^{3}$ ). The virgin bitumen used was 70/100 pen, obtained from Kuwait Petroleum, with density $1032 \mathrm{~kg} / \mathrm{m}^{3}$. Additionally, steel wool fibers were added to the mixture. The material used in the steel wool was lowcarbon steel, with density $7180 \mathrm{~kg} / \mathrm{m}^{3}$. These fibers had 4 different diameters, $0.02855 \mathrm{~mm}$ (type 0000), $0.03642 \mathrm{~mm}$ (type 00),
FIG. 1

(a) Image of steel wool fibers type 00 (0.03642 diameter) in dense asphalt concrete. (b) SEM image of a steel wool fiber type 0000 (0.02855 diameter).
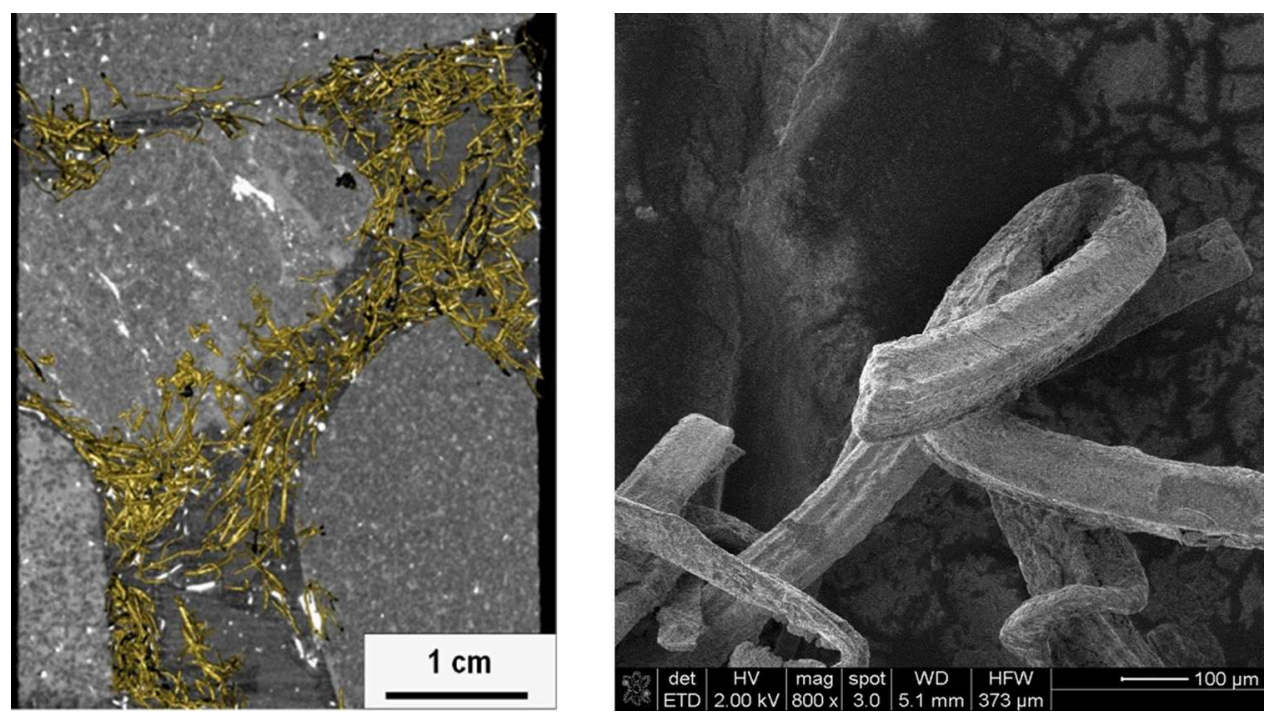
TABLE 1 Composition of the dense asphalt mixture with steel wool fibers.

\begin{tabular}{|c|c|c|c|}
\hline Sieve Size $(\mathrm{mm})$ & $\begin{array}{l}\text { Aggregate Weight } \\
\text { \% Retained }\end{array}$ & $\begin{array}{l}\text { Cumulative Aggregate } \\
\text { Weight \% Retained }\end{array}$ & Weight $(\mathrm{g})$ \\
\hline $11.2-8.0$ & 15 & 15 & 2325 \\
\hline $8.0-5.6$ & 15 & 30 & 2325 \\
\hline $5.6-4.0$ & 10 & 40 & 1550 \\
\hline $4.0-2.8$ & 10 & 50 & 1550 \\
\hline $2.8-2.0$ & 10 & 60 & 1550 \\
\hline $2.0-1.4$ & 7 & 67 & 1085 \\
\hline $1.4-1.0$ & 6 & 73 & 930 \\
\hline $1.0-0.5$ & 9 & 82 & 1395 \\
\hline $0.5-0.25$ & 6 & 88 & 930 \\
\hline $0.25-0.09$ & 5 & 93 & 775 \\
\hline$<0.063$ & 7 & 100 & 1085 \\
\hline \multirow[t]{6}{*}{ Bitumen $70 / 100$. (\% of Weight of Mixture) } & (\% of Weight of Mixture) & 6 & 868 \\
\hline & & 5.25 & 814 \\
\hline & & 5 & 775 \\
\hline & & 4.75 & 736 \\
\hline & & 4.5 & 697 \\
\hline & & 4.25 & 659 \\
\hline Steel Fibers & Length & Diameter & \\
\hline (\% volume of Bitumen) & $(\mathrm{mm})$ & $(\mathrm{mm})$ & \\
\hline \multirow[t]{2}{*}{$2 \%$ Fibers } & 2.5 and 7 & 0.02855 (Type 0000) & 132 \\
\hline & & 0.03642 (Type 00) & \\
\hline $4 \%$ Fibers & & 0.08389 (Type 1) & 264 \\
\hline $6 \%$ Fibers & & 0.15498 (Type 3) & 396 \\
\hline
\end{tabular}

$0.08389 \mathrm{~mm}$ (type 1 ) and $0.15498 \mathrm{~mm}$ (type 3 ), and two different initial lengths: short fibers, with approximately $2.5 \mathrm{~mm}$ average length and long fibers, with around $7 \mathrm{~mm}$ average length). Finally, 4 different amounts of fibers were used: $0,2,4$, and $6 \%$, by total volume of bitumen in the mixture (see Table 1). In total, 25 different types of mixtures were prepared; 24 with different original sizes, types, and volumes of fibers and 1 without steel fibers (reference mixture), always maintaining the same mass of aggregates and bitumen, but changing the mass of fibers.

\section{TEST SPECIMENS PREPARATION}

The materials were mixed in a laboratory planetary mixer at a mixing speed of $312 \mathrm{rpm}$. Two mixture batches were prepared for each of the 25 asphalt concrete mixtures studied. The amount of material in each mixture was something more than $16 \mathrm{~kg}$. Materials were heated to $160^{\circ} \mathrm{C}$ before mixing. The raw materials were added to the bowl in the following order: first the bitumen and the fibers, then the coarse aggregates, the sand and finally, the filler. Materials were mixed during approximately $5 \mathrm{~min}$.

The first batch was used to make cylindrical Marshall specimens with $10 \mathrm{~cm}$ diameter, approximately $6 \mathrm{~cm}$ height, and exactly $1190 \mathrm{~g}$ of mass. Immediately after placing the specimens in the mould, they were heated to $140^{\circ} \mathrm{C}$ and compacted with a
Marshall hammer, applying 50 blows on each face of the specimens. For each mixture, 4 cylindrical specimens were used.

The second $16 \mathrm{~kg}$ batch was used for preparing asphalt concrete slabs. These slabs were compacted by using a pneumatic laboratory wheel compactor [15]. Before the compaction started, the specimen was subjected to a pre-compaction with a low tire pressure $(0.1 \mathrm{MPa})$ and a low maximum wheel load $(1 \mathrm{kN})$. The effective compaction of the rolling-wheel specimen was performed at higher tire pressure $(0.6 \mathrm{MPa})$ and a constant wheel load $(5 \mathrm{kN})$. After the compaction, both faces of the samples were polished until they reached a height of $5 \mathrm{~cm}$. From this, blocks of 25 by $25 \mathrm{~cm}^{2}$ were sawn (see Fig. 2(a)).

Finally, from these blocks, prismatic specimens of 12 by 5 by $5 \mathrm{~cm}^{3}$ were cut (see Fig. $2(\boldsymbol{b})$ ). Additionally, a $3 \mathrm{~mm}$ wide and $8 \mathrm{~mm}$ deep notch was created in the test samples; the notch was cut at the midpoint in the direction of the loading from the central axis of the sample. In total, more than 120 specimens were tested.

\section{AIR VOID CONTENT}

The air void content was calculated in a geometrical way. For that, the exact height and weight of 4 cylindrical test specimens for each mixture were measured in order to calculate the bulk density of each specimen. Additionally, as the exact percentage of materials and their density for each mixture were known, the 
FIG. 2 Test samples used in the paper: (a) slabs, and (b) prismatic specimens.

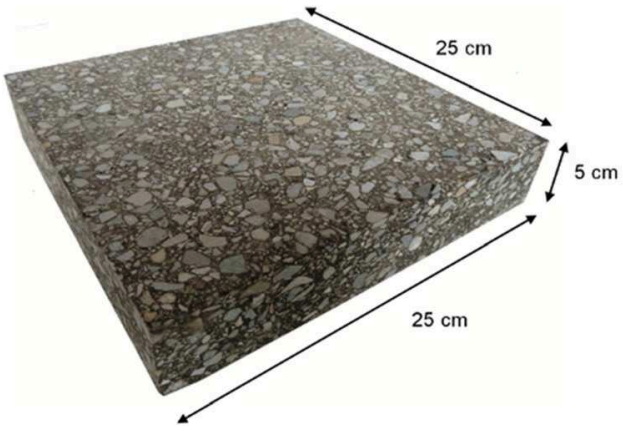

(a)

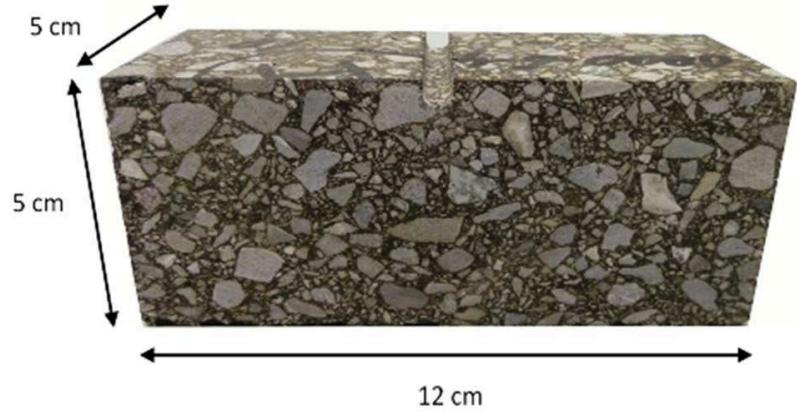

(b) theoretical density without voids for each mixture was found. From this, the air voids percentage was calculated as

(1) $\quad$ Void content $=\left(1-\frac{\rho_{b}}{\rho_{t}}\right) \times 100$

where $\rho_{b}$ is the bulk density of the mixture and $\rho_{t}$ is the theoretical density without voids of the mixture.

\section{LENGTH OF THE STEEL FIBERS BEFORE AND AFTER MARSHALL COMPACTION}

The average length of 50 fibers, before the mixing process and extracted from each mixture containing fibers, was measured by taking photographs under an optical microscope and by measuring the individual fibers length with an image processing program (ImageJ). Fibers were obtained by dissolving the bitumen in toluene and by extracting them with a magnet. Moreover, the average diameter of the fibers was calculated from 12 individual fibers for each type.

\section{MEASUREMENTS OF FIBERS CLUSTERS}

Fiber clusters in the mixtures were measured by taking photographs of both faces from the 25 by 25 by $5 \mathrm{~cm}^{3}$ slabs and by analysing the clusters with ImageJ. An example of one of the analysed pictures is represented Fig. 3. The percentage of clusters in the mixture was calculated as

(2) $\quad$ Percentage of clusters $=\frac{1}{2}\left(\frac{A_{c 1}}{A_{P 1}}+\frac{A_{c 2}}{A_{P 2}}\right)$

where:

$A_{c 1}$ and $A_{c 2}=$ the area of clusters in the upper and the lower faces of the slab, respectively, and

$A_{p 1}$ and $A_{p 2}=$ the areas of the upper and the lower faces of the slab, respectively.

\section{PARTICLE LOSS RESISTANCE}

One of the main purposes of fibers in dense asphalt concrete would be to prevent damage in roads, especially ravelling or potholes. For this reason, particle loss resistance tests were chosen to evaluate the effect of steel wool fibers on the abrasion properties of the mixture.

Test samples were conditioned at a temperature of $20^{\circ} \mathrm{C}$ during $24 \mathrm{~h}$, in the same temperature controlled room where the test setup was installed. In this way, each sample was subjected to 300 revolutions at $30 \mathrm{rpm}$ in the steel drum without steel balls. The mass of the specimen before and after the test was noted, and the particle loss was calculated using Eq 3. Measurements were taken from 3 Marshall cylinders.

(3) $\quad$ Particle loss $=\left(\frac{w_{1}-w_{2}}{w_{1}}\right) \times 100$

where:

$w_{1}=$ the initial sample weight, and

$w_{2}=$ the final sample weight.

FIG. 3 Cluster distribution in the asphalt concrete slabs surface of 25 by $25 \mathrm{~cm}^{2}$.

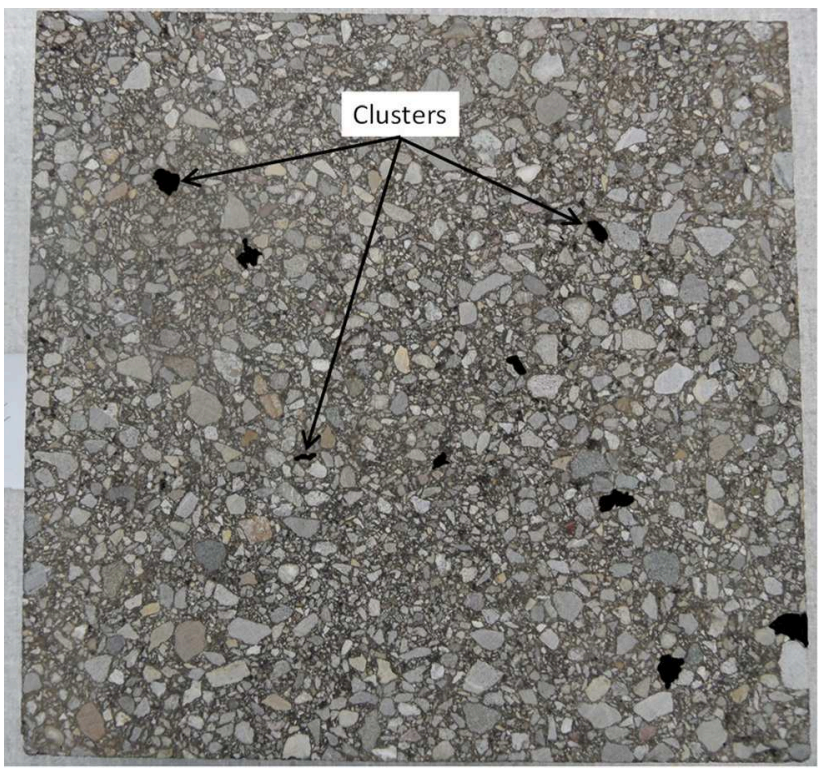


FIG. 4

(a) Thermal conductivity measurement device. (b) Induction heating device.

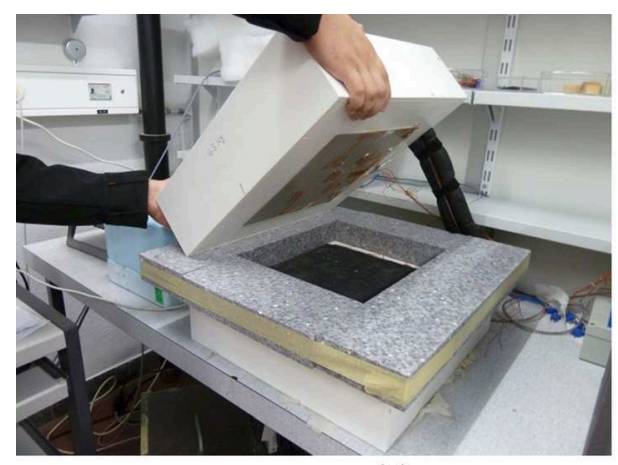

(a)

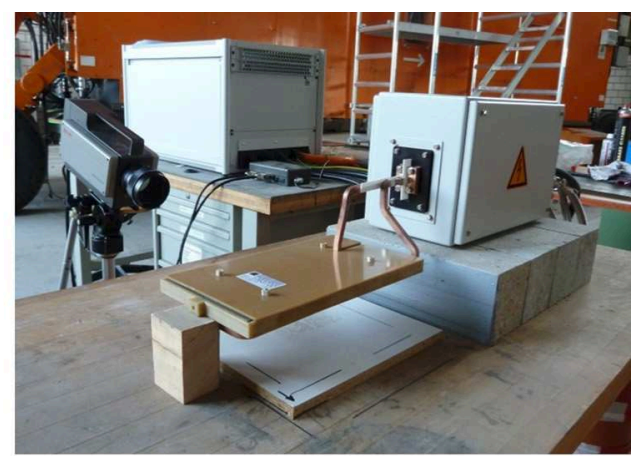

(b)

\section{FLEXURAL STRENGTH}

Flexural strength of dense asphalt concrete specimens was measured in the test samples shown in Fig. $\mathbf{2}(\boldsymbol{b})$. All tests were performed inside an environmental chamber at $-20^{\circ} \mathrm{C}$. Prior to testing, test specimens were kept in the environmental chamber at the test temperature for $2 \mathrm{~h}$ to avoid any temperature gradient within the samples. The test setup consisted in two supporting rollers at the straight (bottom) edge and a loading roller at the midpoint beam. The spacing between the two supports was $8 \mathrm{~cm}$. The equipment used for testing was a Dynasphalt $10 \mathrm{kN}$ and the load was applied upon breakage at a rate of $0.05 \mathrm{~mm} / \mathrm{min}$. Tests were stopped when the force in the discharge curve of the beams reached $20 \mathrm{~N}$. This load was enough to produce a crack of approximately $200 \mu \mathrm{m}$ width crossing the specimen from the tip of the notch to the load application point.

\section{THERMAL CONDUCTIVITY MEASUREMENTS}

The thermal conductivity measurements were done through the hot plate method (Fig. 4(a)), as explained in Ref. [16]. It consisted of a flat, heated metering plate and a cooled plate in between which the test specimen is placed. The system was surrounded on all lateral sides by an isolating layer, which provided adiabatic conditions. In this case, the lower plate was at a constant temperature of $5^{\circ} \mathrm{C}$ and the upper plate at a constant temperature of $50^{\circ} \mathrm{C}$. These conditions were maintained during $24 \mathrm{~h}$ to secure a stable temperature flux through the specimen.

\section{INDUCTION HEATING MEASUREMENTS}

To prove that asphalt mortar could be heated with induction energy, the slabs were heated during $1 \mathrm{~min}$, starting at a temperature of $20^{\circ} \mathrm{C}$. Their temperature change was measured with a 640 by 480 pixels, full colour infrared camera. The induction heating experiment was performed by using an induction a $30 \mathrm{~kW}$ induction heating generator able to generate a maximum frequency of $78 \mathrm{kHz}$ (Fig. 4(b)) [16].

\section{BITUMEN RHEOLOGY}

The asphalt binder of the mixtures was recovered by rotary evaporator in order to determine the temperature when Newtonian behaviour occurs. Therefore, the dynamic shear properties of bitumen were measured with a Physica MCR 301 dynamic shear rheometer (Anton Paar GmbH., Austria) in a configuration with $25 \mathrm{~mm}$ diameter parallel plates with a $1 \mathrm{~mm}$ gap. Oscillatory frequency sweeps were carried out over a range of 0.001 to $0.1 \mathrm{~Hz}$ at temperatures from 30 to $70^{\circ} \mathrm{C}$ under a constant strain of $0.1 \%$ within the linear viscoelastic region. The complex viscosity $\left(\eta^{*}\right)$ as a function of frequency $(\omega)$ at different temperatures was recorded automatically during the tests.

\section{HEALING MEASUREMENTS}

The healing of asphalt concrete prismatic specimens was done as follows: first the tests specimens were numbered; then, with the help of a random number generator, they were selected for heating during $0.5,1,1.5,2$, and $2.5 \mathrm{~min}$, respectively. Later, they were tested under three-point bending as it is described in the Flexural Strength Section. After this, the test specimens were let to rest during $2 \mathrm{~h}$ at $20^{\circ} \mathrm{C}$ and heated during the time selected.

Finally, the test samples were tested again under threepoint bending. The healing level $(S(\tau))$ of asphalt mastic was defined as the relationship between the ultimate force of the test specimens during a three point bending test, $F_{0}$, and the ultimate force measured in the beams after the healing process $F(\tau)$, where $\tau$ is a parameter that represents the amount of energy introduced in the asphalt concrete test sample:

(4)

$$
S(\tau)=\frac{F(\tau)}{F_{0}}
$$

where $\tau$ is a parameter that quantifies the amount of heat introduced in the test samples. 
FIG. 5 Average length of the fibers before and after mixing and compacting.

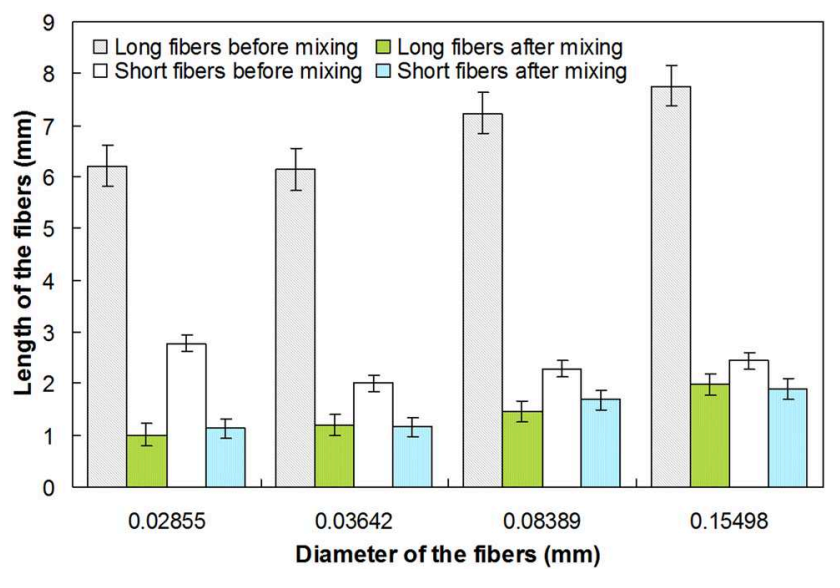

\section{Results and Discussion}

\section{EFFECT OF MIXING AND COMPACTING ON THE LENGTH OF STEEL WOOL FIBERS}

In Fig. 5, the average length of the fibers before and after mixing is shown. It can be observed that in the case of the long fibers there is a reduction of more than 6 times their original length. This is especially remarkable for fibers with $0.15498 \mathrm{~mm}$, diameter in the cases where the average original length was $7.753 \mathrm{~mm}$ and $2.437 \mathrm{~mm}$, respectively. However, after mixing and Marshall compaction, the average length of the fibers was $1.981 \mathrm{~mm}$ for the long fibers and $1.894 \mathrm{~mm}$ for the short fibers. Additionally, it can be observed that the final length of the fibers after mixing and compacting increases with their diameter. For example, in the case of fibers which are initially short, the final length of those with $0.02855 \mathrm{~mm}$ diameter is $1.129 \mathrm{~mm}$, while the final length of fibers with $0.15498 \mathrm{~mm}$ diameter is $1.894 \mathrm{~mm}$. The reason for this is the higher tensile resistance of the fibers with big diameter. Moreover, a clear difference in the final length of fibers that were initially short and fibers that were originally long cannot be appreciated.

\section{CLUSTERS EXISTENCE AND AIR VOID CONTENT}

Moreover, in the research it was observed that clusters of fibers appeared during the mixing process. In Fig. 6, the percentage of clusters of fibers in the mixtures, after mixing and compacting is shown. When the fibers are initially long, the final amount of clusters is slightly higher than when fibers are initially short. The average percentage of clusters the mixture for short fibers is $0.35 \%$, while the average percentage of clusters for long fibers is $0.41 \%$. Additionally, the amount of clusters grows with the percentage of fibers. It is remarkable that the highest amount of clusters appeared for fibers with $0.00635 \mathrm{~mm}$ diameter, while the minimum was for fibers with $0.1143 \mathrm{~mm}$ diameter. This was influenced by the total number of fibers in the mixture and was higher for the fibers with short diameter.

Furthermore, in Fig. 7, it can be seen that the lowest air voids content is obtained for the reference mixture, without fibers ( $1.51 \%$ air void content). Additionally, mixtures with $2 \%$ long fibers, with $0.1143 \mathrm{~mm}$ diameter have a much lower air void content than the rest of the mixtures with $2 \%$ long fibers. This happened because, in the specific case when $2 \%$ of fibers were used, there were more clusters in mixtures with long fibers than in mixtures with short fibers. Additionally, in the cases where $4 \%$ long fibers with $0.02855 \mathrm{~mm}$ diameter and $0.03642 \mathrm{~mm}$ diameter are used, the air void content is very similar to the corresponding cases where $2 \%$ of fibers were applied. Besides, the air void content in all the mixtures with $6 \%$ fibers was much higher than the air void content in the rest of the mixtures. This happened because the number of fibers in the mixture was very high; their specific surface was also quite high. It can also be noticed that the air void content in case of $6 \%$ fibers remained the same regardless of the length of fibers and

FIG. 6 Area percentage of clusters in the mixture versus the max diameter of fibers in (a) mixes with long fibers and (b) mixes with short fibers.

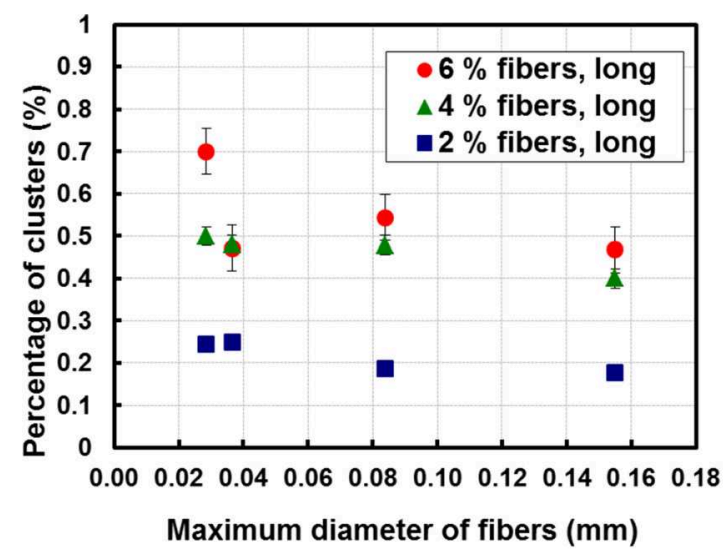

(a)

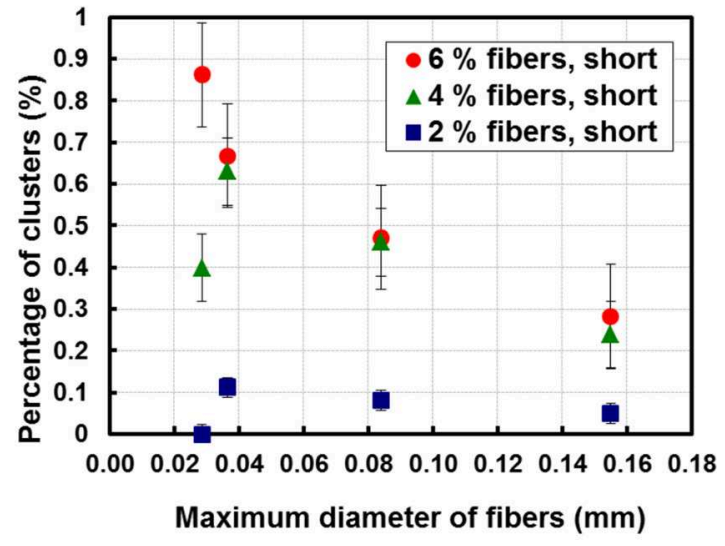

(b) 
FIG. 7 Air void content versus max diameter of fibers in (a) mixes with long fibers and (b) mixes with short fibers.

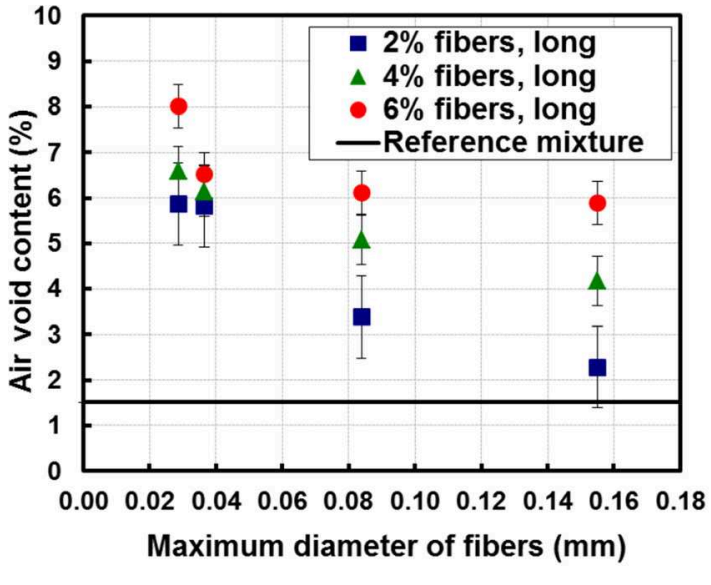

(a)

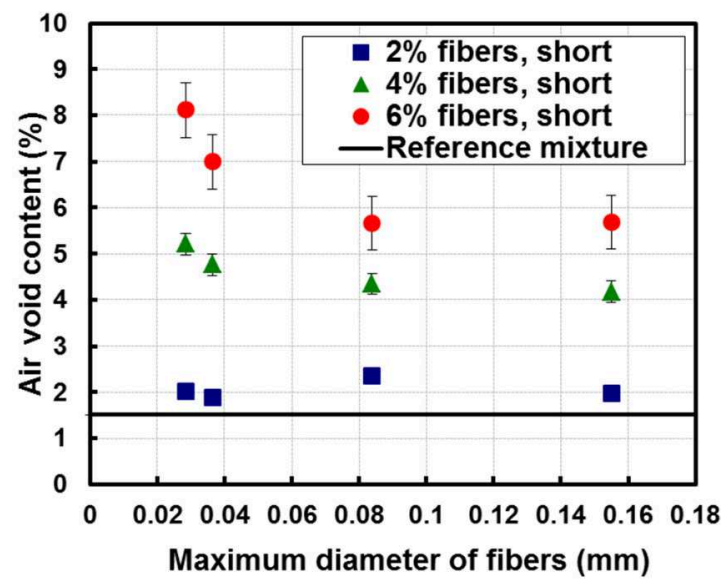

(b) did not change for fibers with a maximum diameter above $0.08389 \mathrm{~mm}$.

\section{PARTICLE LOSS RESISTANCE OF DENSE ASPHALT CONCRETE WITH STEEL WOOL FIBERS}

In Fig. 8, the particle loss percentages of dense asphalt concrete cylinders, with fibers embedded are shown. From Fig. $\mathbf{8}$, it can be observed that the particle loss decreases gradually with the increase on the diameter of fibers. This effect is more evident in the mixtures where long fibers were used. Good examples of this were the mixtures where $6 \%$ of fibers with $0.02855 \mathrm{~mm}$ diameter were used. In these cases, an abrasion loss of more than $10 \%$ could be observed, while in the cases where $6 \%$ of fibers with $0.15498 \mathrm{~mm}$ diameter were used, the abrasion loss was almost $2 \%$, which is lower than that of the reference mixture $(3.22 \%)$. In general, mixtures with short fibers showed a minor abrasion resistance loss than mixtures with long fibers. This was especially true in the cases where fibers with thinner diameters were used $(0.02855 \mathrm{~mm}$ and $0.03642 \mathrm{~mm}$ ). Moreover, from these experiments it is still unclear if steel wool fibers can improve the abrasion loss resistance of dense asphalt concrete.

Moreover, in Fig. 9, the relationship between the particle loss resistance of dense asphalt concrete with fibers and the air void content of the asphalt concrete mixtures has been represented. It can be observed that the particle loss percentage increases exponentially with the increase of the air void content in the mixture. Additionally, it has been found that dense asphalt concrete with $2 \%$ of steel wool fibers shows higher particle loss than mixtures with 4 and $6 \%$ of steel wool fibers. In a word, steel wool fibers improve the abrasion resistance of dense asphalt concrete, but as the air void content increases with the volume of fibers, its beneficial effects are reduced.

FIG. 8 Particle loss percentage of dense asphalt concrete cylinders versus the max diameter of fibers in (a) mixes with long fibers and (b) mixes with short fibers.

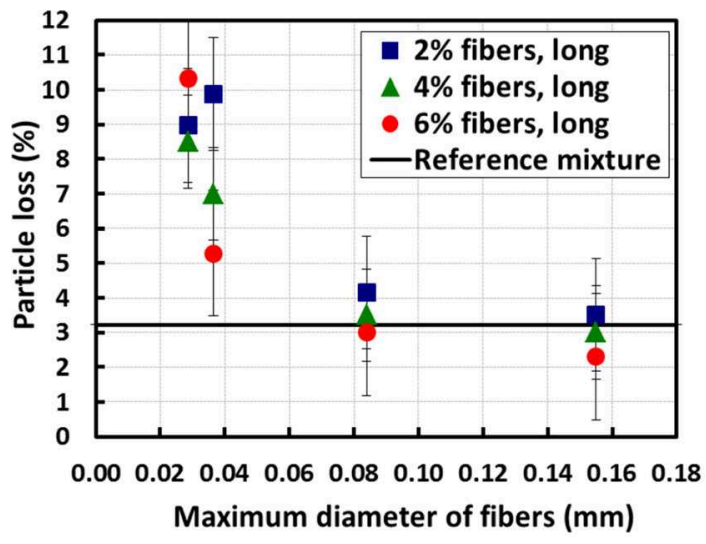

(a)

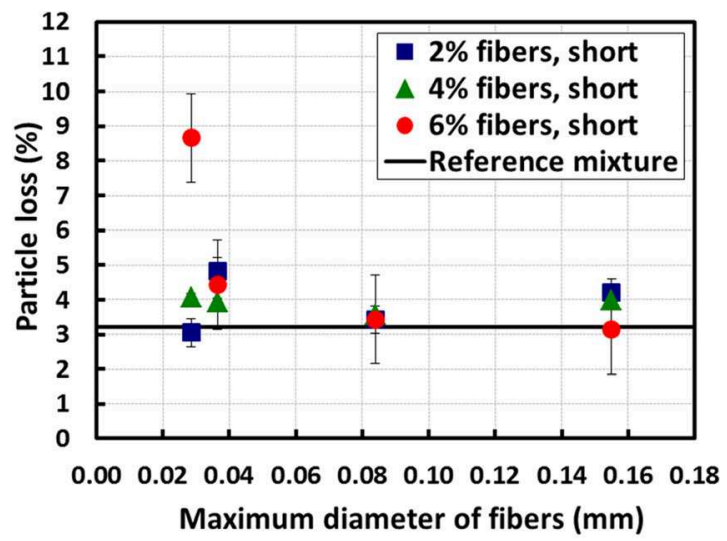

(b) 
FIG. 9 Particle loss percentage of dense asphalt concrete cylinders versus their air void content.

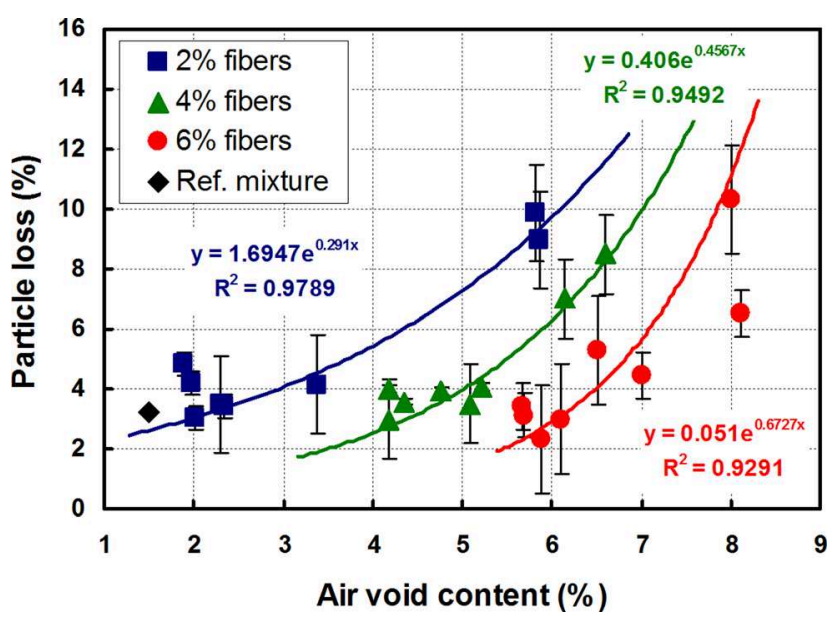

\section{THREE POINT BENDING STRENGTH OF DENSE ASPHALT CONCRETE BEFORE HEALING}

In Fig. 10, the probability-probability plot of the maximum strength resisted by the asphalt concrete test samples before healing, tested under 3 point bending is shown. These test samples had 2, 4, and $6 \%$ of steel wool fibers, with 4 diameters and various initial lengths. All of them had a very similar strength (average strength $6.61 \mathrm{kN}$ and standard deviation $0.75 \mathrm{kN}$ ). In addition, when they are represented in a P-P plot, it can be observed that their probabilities align in an almost perfect straight line. This is an indication that their 3-point bending strength can be considered constant, independently of the amount of fibers or of their characteristics. This coincides with the results presented in Ref. [7] for materials with the same amount of steel fibers, although with a different geometry,and in Ref. [3], where it was reported that the amount or diameter of steel wool fibers had no effect on the indirect tensile strength of porous asphalt concrete.

FIG. 10 Probability-probability plot of the max strength resisted by the asphalt concrete test samples before healing.

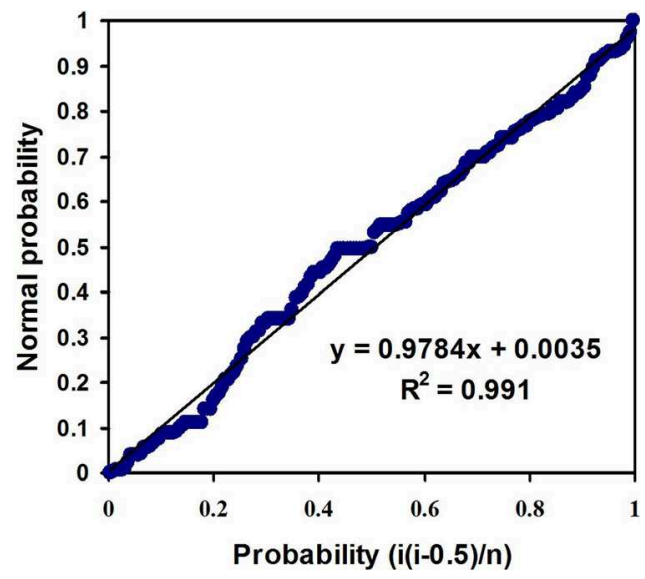

THERMAL PROPERTIES OF DENSE ASPHALT CONCRETE WITH STEEL WOOL FIBERS

The thermal conductivity of asphalt concrete can be influenced by the volume, size, and individual thermal conductivity of the components inside the mixture. Therefore, it is possible to control the effective thermal conductivity of a composite through selecting the components and designing the structure. However, there is not an easy way to calculate the thermal conductivity of a composite, although there are different methods for various types of materials [17]. It is known that when a volumetric part of a composite material is increased or decreased, the thermal conductivity of the total composite will also increase or decrease. It is also known that when one of the elements of a composite material is increased in a sufficient amount it might percolate, producing a sudden increase of several orders of magnitude in the electrical conductivity. However, it is also known that in this case, the thermal conductivity will not change abruptly [18].

In Fig. 11, the thermal conductivity results for all the mixtures analysed are shown. In Fig. 11(a), the thermal conductivity is represented versus the air void content of asphalt concrete and in Fig. 11(b), the thermal conductivity is represented versus the diameter of fibers. In Fig. 11(a), it can be observed that in the mixtures without steel wool fibers the thermal conductivity reduces with the increase in the air void content, from $1.6 \mathrm{Wm}^{-1} \mathrm{~K}^{-1}$ to $1.2 \mathrm{Wm}^{-1} \mathrm{~K}^{-1}$ when the porosity is 2.91 and $11.90 \%$, respectively. These results agree with previously ones reported in the literature [19]. The reason for this reduction is that above a certain percentage of air voids, the pores start being connected, and the total asphalt concrete surface exposed to the air is much higher. Moreover, it is well-known that the thermal conductivity of steel is much higher than the thermal conductivity of asphalt concrete [20]; as a result, in Fig. 11(a) it can be seen that the conductivity of asphalt concrete mixtures with steel wool fibers is slightly higher than the conductivity of asphalt concrete mixtures without steel fibers, even with the same air void content. The increase in the thermal conductivity is not very high because the maximum volumetric percentage of steel wool fibers in the mixture is $2.21 \%$, which is not enough to have a significative effect in the mixture.

Finally, in Fig. 11(b), the thermal conductivity has been represented against the diameter of fibers. It can be observed that the influence of the diameter of fibers in the thermal conductivity cannot be appreciated. In the case of the mixtures without fibers, the air void content in the mixture seems to have a more clear effect in the thermal conductivity, although more tests are needed to confirm this point. As a conclusion, it is important to minimize the influence of the fibers on the air void content. To increase the thermal conductivity of asphalt concrete, the diameter and percentage of the electrically conductive fibers should be as high as possible, while the mechanical properties of the mixture are not damaged. 
FIG. 11 Thermal conductivity of asphalt concrete (a) versus the air void content and (b) versus the diameter of fibers.

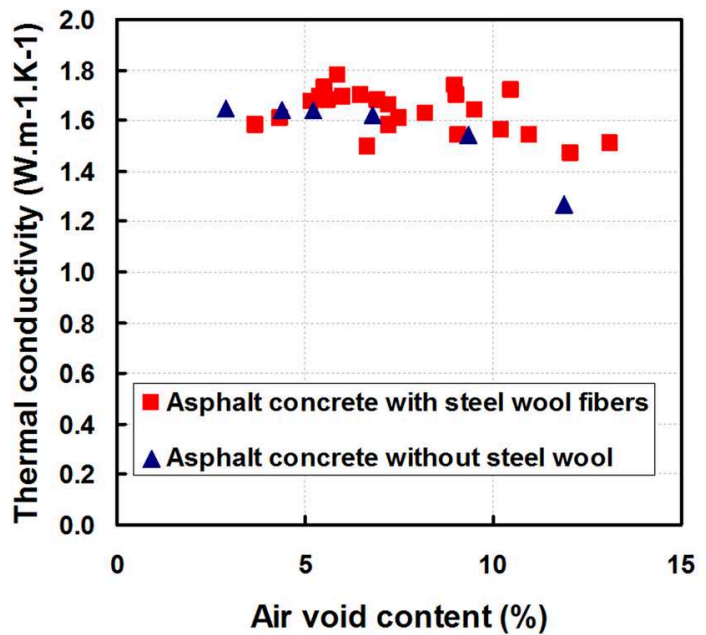

(a)

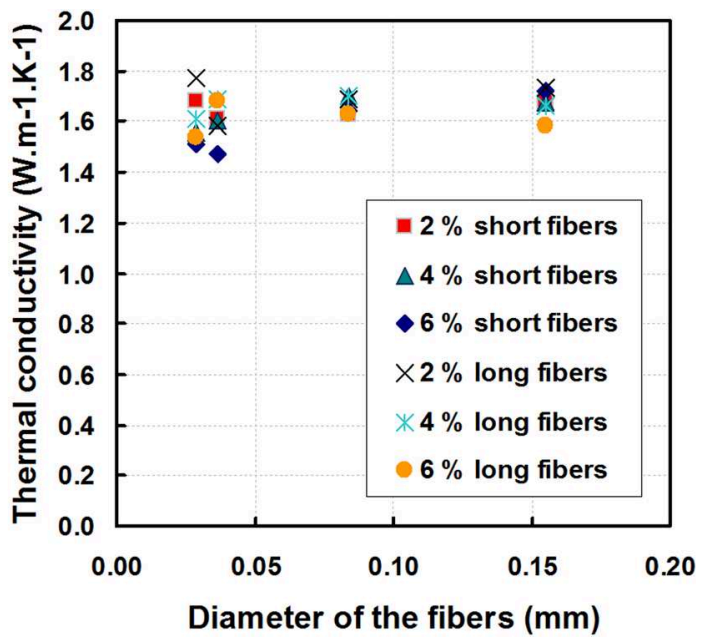

(b)

\section{INDUCTION HEATING PROPERTIES OF DENSE ASPHALT CONCRETE WITH STEEL WOOL FIBERS}

In Fig. 12, the maximum temperature reached in dense asphalt concrete after heating during $1 \mathrm{~min}$ has been represented. In this picture, it can be observed that the maximum temperature reached depends on the diameter and percentage of fibers in the mixture. For example, in Fig. 12 it can be observed that the temperature reached in mixtures with $6 \%$ fibers of $0.02855 \mathrm{~mm}$ diameter is approximately $60^{\circ} \mathrm{C}$, while the temperature reached in mixtures with fibers of $0.15498 \mathrm{~mm}$ diameter is approximately $90^{\circ} \mathrm{C}$. Moreover, in Fig. 12 it can be observed that the amount of fibers has a very high impact in the maximum temperature reached by the mixture. For example, in mixtures with

FIG. 12 Maximum temperature reached after 1 min heating versus the max diameter of fibers

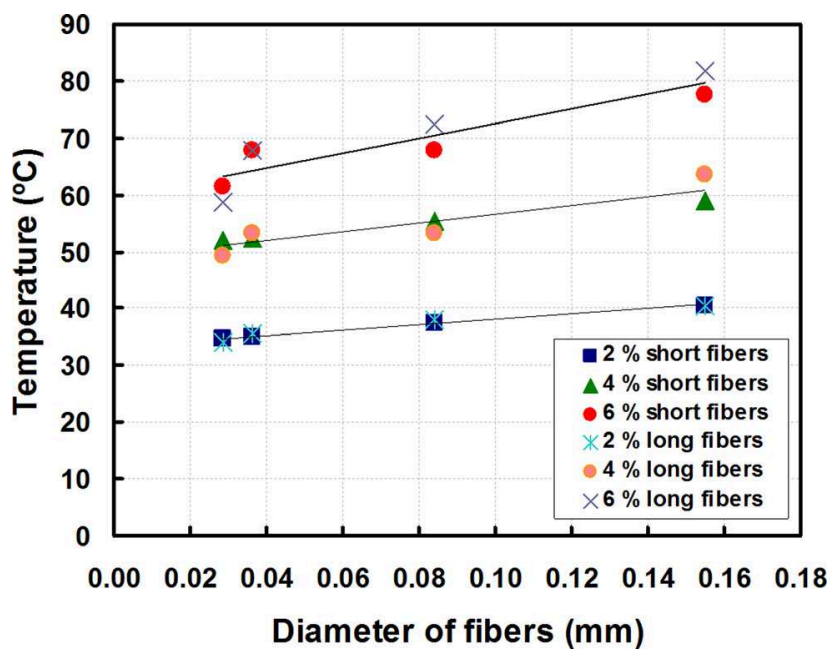

fibers of $0.08389 \mathrm{~mm}$ diameter, the maximum temperature reached after $1 \mathrm{~min}$ heating is approximately 38,55 , and $71^{\circ} \mathrm{C}$ for mixtures with 2,4 , and $6 \%$, respectively.

In Ref. [6], it is explained that the temperature reached by asphalt concrete will increase linearly with the volume of fibers in the mixture, while the temperature will increase in a factor 4 with the diameter of the fibers. Although in the cases where the mass of fibers is fixed and the diameter of the fibers increases, the number of fibers in the mixture will decrease. In this way, the influence of the diameter of fibers in the increase of temperature is limited, especially in the cases where a small percentage of fibers had been added to the mixture. Additionally, in Ref. [5], it was shown that the increase of the volume of conductive particles in the mixture will increase the temperature only until a certain level of particles is reached. This level of particles is approximately $6 \%$. The reason why more fibers do not increase the temperature of the mixture is because asphalt concrete reaches a saturation point when more fibers are introduced and there is not enough bitumen to cover them, the temperature cannot be transferred to asphalt concrete and heat is dissipated in the air.

As a conclusion, it can be observed that the maximum temperature reached changes according the diameter and percentage of fibers in the mixture. In the paper, it was observed that the relationship between the air void content, the thermal conductivity or the electrical resistivity and the volume and type of steel wool fibers with the maximum temperature reached is not as clear as the relationship between the type and volume of fibers with the maximum temperature reached. For this reason, it can be concluded that the three first parameters do not really have a strong influence on the induction heating temperature reached by asphalt concrete. 
FIG 13 (a) Complex viscosity $\left(\eta^{*}\right)$ as a function of shear frequency at temperatures from 40 to $70^{\circ} \mathrm{C}$ and (b) flow behavior index ( $n$ ) at different temperatures.

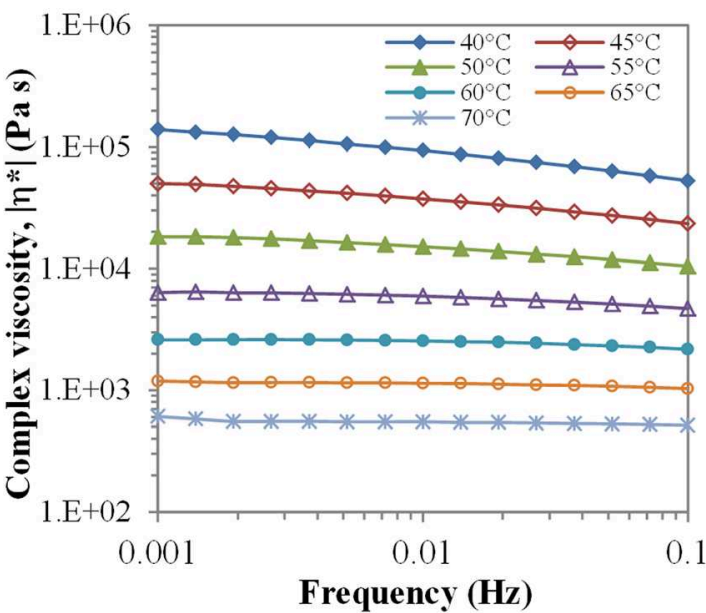

(a)

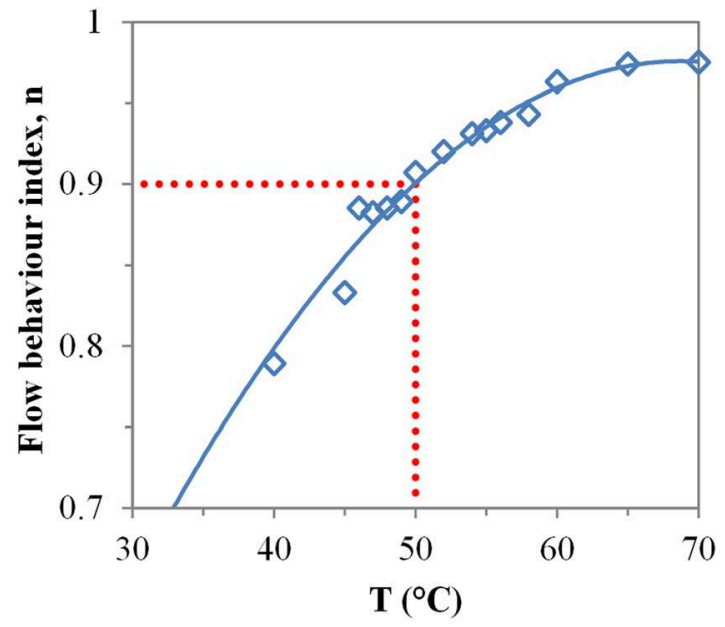

(b)

\section{RHEOLOGICAL PROPERTIES OF THE BITUMEN EXTRACTED FROM DENSE ASPHALT CONCRETE}

Bitumen can act like a Newtonian liquid at high temperatures. Nevertheless, it presents a viscoelastic behaviour which is dependent on temperature and time of loading [21]. The determination of the dynamic flow properties of the recovered bitumen was accomplished by oscillatory frequency sweeps at constant strain in order to find out when the tested binder reaches a near-Newtonian flow behaviour. Figure 13(a) shows the effect of frequency on the complex viscosity $\left(\eta^{*}\right)$ of the extracted bitumen at different temperatures. To analyse the deviation of the bitumen behaviour from Newtonian, the rheological data have been fitted through the following power law relationship [22]:

(5)

$$
\eta *=m|\omega|^{n-1}
$$

where:

$\omega=$ the frequency, and

$\eta^{*}=$ the complex viscosity, being $m$ and $n$, the fitting parameters.

The dimensionless parameter $n$ is also called the flow behaviour index; $n=1$ corresponds to a Newtonian fluid and $n<1$ reflects a higher degree of pseudoplastic properties of the fluid. As the transition from pseudoplastic to Newtonian behaviour is not clearly defined for bitumen in literature, in this study it has been considered that the bitumen properties can be considered Newtonian when the flow behaviour index is higher than 0.9. This transition from $0.9 \leq n<1$ is also known as near near-Newtonian behaviour [23].

In Fig. 13(a), it can be seen that at the higher testing temperatures this bitumen presents a near-Newtonian behaviour where the complex viscosity is relativity independent of the shear frequency applied. In contrast, at lower temperatures, the complex viscosity decreases with the increasing of the frequency, exhibiting shear-thinning behaviour (pseudoplasticity). Moreover, the flow behaviour indexes $(n)$ obtained at different temperatures are plotted in Fig. 13(b). It can be observed that the flow behaviour index increased with the increase of temperature, getting close to 1 (ideal Newtonian behaviour). Attending to this condition, it can be concluded that the tested bitumen behaves as a near-Newtonian fluid at temperatures above $50^{\circ} \mathrm{C}$. This transition temperature is associated to the type of bitumen and ageing level, varying for other bitumens and ageing states.

\section{ASPHALT SELF-HEALING RESULTS}

In Fig. 14, the healing level of asphalt concrete versus the average temperature of the test samples is shown. All the results obtained from different test samples with different percentages and diameters of steel wool are represented. One of the most remarkable points is that all the results for the different

FIG. 14 Healing data versus average temperature in the test samples.

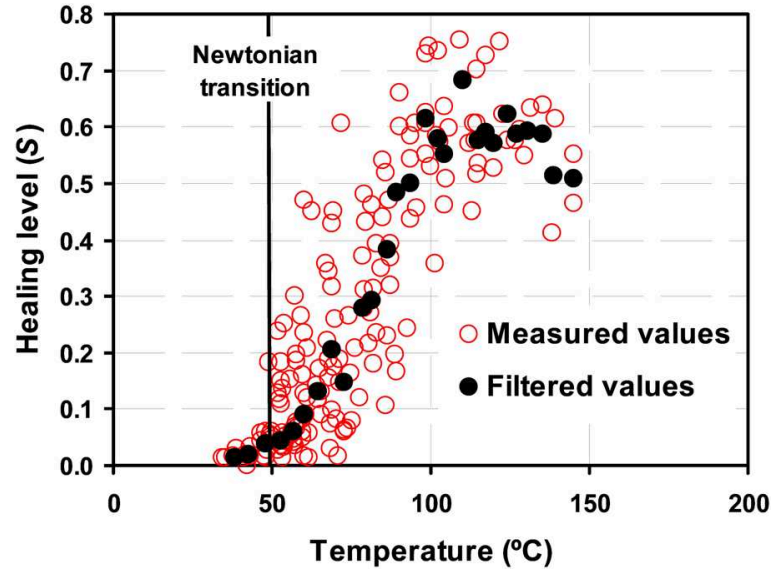


materials align in a single curve. In this figure, it can be observed that the healing, so as the point dispersion starts at approximately $50^{\circ} \mathrm{C}$, is the moment when bitumen has a near to Newtonian behaviour. From this point, the healing levels increase with the temperature in the test samples until approximately 0.6 , which happened at around $100^{\circ} \mathrm{C}$.

In the case of the test samples studied, as they were heated without a mould, their shape changed constantly with temperatures above $50^{\circ} \mathrm{C}$. This made it so the healing levels could not be 1 , as it happened in Ref. [2], where the test samples were contained in the same moulds where they had been built. Besides, these results are lower to the ones shown in Ref. [24] for porous asphalt concrete where the highest healing levels reached approximately 0.8 . A higher healing level was not reached because the geometry of the test samples was different than the geometry of the test samples in this article. Additionally, to improve the understanding of the data, in Fig. 14 the healing results have been filtered by using a moving average filter and represented.

From these data, and after comparing them with those presented in Ref. [2], it can be concluded that the most appropriate way for healing asphalt concrete is to increase the temperature above the Newtonian transition (see Fig. 14) and maintain it for a certain amount of time. For this reason, an optimum asphalt concrete material for self-healing applications will be one with as low a thermal conductivity as possible so that the energy is not dissipated in the environment. With this, healing may happen at lower temperatures, and the global efficiency of the system will be increased.

\section{Conclusions}

This paper studies and quantifies which parameters more influence the addition of fibers into asphalt concrete. For that, mixtures with different amounts and diameters of flexible steel fibers were built. It was found that steel wool fibers can be mixed in asphalt concrete without forming clusters. Additionally, it could be seen that the most critical parameters to get a good dispersion of fibers in the mixture are first the amount of fibers, and second their diameter, and third the length.

During this research, it could be observed that the final length of the fibers after mixing and compacting asphalt concrete is independent of the original length which they had when they were added to the mixture. Additionally, it was found that many clusters of fibers appear during the first moments of mixing and that the mixing process serves for dissolving the clusters. Moreover, it was found that the area percentage of clusters grows with the amount of fibers in the mixture and when the diameter of the fibers is reduced. Finally, it could be observed that the original length of the fibers have a high impact on the amount of clusters in the mixture. This happens especially in the case of the thin fibers; however, the influence of the fiber's length reduces with the increase of the fiber's diameter. Furthermore, the air void content in the asphalt concrete increased with the number of fibers in the mixture. It was also found that the air void content grew when the area percentage of clusters in the asphalt concrete was higher regardless of the percentage of fibers and length of fibers, starting with the air void of the reference mix with $1.51 \%$.

Besides, it has been discovered that steel wool fibers do not improve the abrasion loss or tensile strength of dense asphalt concrete. In fact, steel wool fibers might have a negative impact on the abrasion loss performance of the mixture when they are not homogeneously distributed and clusters of fibers appear. Clusters have a direct impact in the air void content of dense asphalt concrete, and in this research, it has been found out that the air void content is a critical parameter affecting the abrasion loss of dense asphalt concrete with fibers. Additionally, it has been observed that mixtures with a higher percentage of fibers have a higher abrasion loss resistance. However, this resistance is not much higher than that of a mixture without steel wool fibers.

In this paper, it has been also observed that the thermal conductivity of dense asphalt concrete reduces with the increase of the air void content in the mixture. It has been also observed that the thermal conductivity can be improved to some extend by the presence of steel wool fibers in the mixture. This happens because the thermal conductivity of steel is much higher than the thermal conductivity of asphalt concrete. It has also been observed that the effect of the steel wool fibers is limited; their amount inside the mixture is very small (less than $2.21 \%$ by volume). Additionally, an increase in the volume of fibers in the mixture implies also an increase in the air void content. Finally, it has been found that the thermal conductivity of asphalt concrete has a very low correlation with the length and diameter of the steel wool fibers.

Moreover, in this paper, the effect of induction heating on the recovery of damaged test samples of dense asphalt concrete tested under 3 point bending has been shown. It has been found that the healing rates of dense asphalt concrete increase with the increase of temperature. In this research, the mechanical resistance of the test samples could be recovered up to $60 \%$ when the material was damaged. This happened at around $100^{\circ} \mathrm{C}$. This recovery value was relatively low because the test samples deformed during induction heating. To reach a certain healing level, it is necessary to heat the test samples above a certain temperature. If the heating time is less, damage will not be fully recovered. Besides, there is a minimum temperature below which asphalt cannot be healed. It coincides with the temperature when bitumen behaves as a near-Newtonian fluid.

Finally, it has been concluded that the most appropriate way for healing asphalt concrete is to increase the temperature above the Newtonian transition and maintain it for a certain amount of time. For this, it is necessary that an asphalt concrete 
material with a very low thermal conductivity be used so that the energy is not dissipated in the environment. With this, healing may happen at lower temperatures and the global efficiency of the system will be increased.

\section{ACKNOWLEDGMENTS}

The writers thank Kuwait Petroleum for providing bitumen. Moreover, the authors acknowledge the financial support from the Swiss Federal Road. Office (ASTRA) and from the FPU Programme of the Spanish Ministry of Education, Culture and Sport.

\section{References}

[1] Ukwuoma, O. and Ademodi, B., "The Effects of Temperature and Shear Rate on the Apparent Viscosity of Nigerian Oil Sand Bitumen," Fuel Process. Technol., Vol. 60, 1999, pp. 95-101.

[2] García, A., "Self-Healing of Open Cracks in Asphalt Mastic," Fuel, Vol. 93, 2011, pp. 264-272.

[3] Garcia, A., Schlangen, E., van de Ven, M., and van Bochove, G., "Optimization of Composition and Mixing Process of a Self-Healing Porous Asphalt," Constr. Build. Mater., Vol. 30, 2012, pp. 59-65.

[4] Gallego, J., del Val, M. A., Contreras, V., and Páez, A., "Heating Asphalt Mixtures with Microwaves to Promote Self-Healing," Constr. Build. Mater., Vol. 42, 2013, pp. 1-4.

[5] García, A., Schlangen, E., and van de Ven, M., "Induction Heating of Mastic Containing Conductive Fibers and Fillers," Mater. Struct., Vol. 44, No. 2, 2010, pp. 499-508.

[6] García, A., Schlangen, E., van de Ven, M., and Liu, Q., "A Simple Model to Define Induction Heating in Asphalt Mastic," Constr. Build. Mater., Vol. 31, 2012, pp. 38-46.

[7] García, A., Norambuena-Contreras, J., and Partl, M. N., “A Parametric Study on the Influence of Steel Wool Fibers in Dense Asphalt Concrete," Mater. Struct., 2013, doi:10.1617/s11527-013-0135-0.

[8] Brown, S. F., Rowlett, R. D., and Boucher, J. L., Asphalt Modification. Proceedings of the Conference on the United States Strategic Highway Research Program: Sharing the Benefits, Thomas Telford, London, 1990.

[9] Huang, H. and White, T. D., "Dynamic Properties of Fiber-Modified Overlay Mixture," Trans. Res. Rec., Vol. 1545, 1996, pp. 98-104.

[10] Wu, S., Ye, Q., Li, N., and Yue, H., "Effects of Fibers on the Dynamic Properties of Asphalt Mixtures," J. Wuhan Univ. Technol., Vol. 22, 2007, pp. 733-736.

[11] Chen, H., Li, N., Hu, C., and Zhang, Z., "Mechanical Performance of Fibers-Reinforced Asphalt Mixture," J. Chang Univ., Vol. 24, No. 2, 2004, pp. 1-5.
[12] Echols, J., "New Mix Method for Fiber-Reinforced Asphalt," Public Works, Vol. 119, No. 8, 1989, pp. 72-73.

[13] Mahrez, A., Karim, M., and Katman, H., "Prospect of Using Glass Fiber Reinforced Bituminous Mixes," J. East Asia Soc. Trans. Studies, Vol. 5, 2003, pp. 794-807.

[14] García, A., Schlangen, E., van de Ven, M., and Liu, Q., "Electrical Conductivity of Asphalt Mortar Containing Conductive Fibers and Fillers," Constr. Build. Mater., Vol. 21, No. 10, 2009, pp. 3175-3181.

[15] Partl, M. N., Flisch, A., and Johnsson, M., "Comparison of Different Compaction Methods Using X-Ray Computer Tomography," Road Mater. Pavements Des., Vol. 8, No. 2, 2007, pp. 139-164.

[16] Garcia, A., Norambuena-Contreras, J., and Partl, M. N., "Experimental Evaluation of Dense Asphalt Concrete Properties for Induction Heating Purposes," Constr. Build. Mater., Vol. 46, 2013, pp. 48-54.

[17] Progelhof, R. C., Throne, J. L., and Ruesch, R. R., "Methods for Predicting the Thermal Conductivity of Composite Systems: A Review", Pol. Eng. Sci., Vol. 15, No. 9, 1976, pp. 615-625.

[18] Bonnet, P., Sireude, D., Garnier, B., and Chauvet, O., "Thermal Properties and Percolation in Carbon NanotubePolymer Composites," Appl. Phys. Lett., Vol. 91, 2007, 201910.

[19] Luca, J. and Mrawira, P. E., "New Measurement of Thermal Properties of Superpave Asphalt Concrete," J. Mater. Civ. Eng., Vol. 17, No. 1, 2005, pp. 72-79.

[20] Powell, B. W., Ho, C. Y., and Liley, P. E., "Thermal Conductivity of Selected Materials," NSRDS-NBS 8, National Standard Reference Data Series, National Bureau of Standards, Gaithersburg, MD, 1996.

[21] García-Morales, M., Partal, P., Navarro, F. J., MartínezBoza, F., Gallegos, C., González, N., González, O., and Muñoz, M. E., "Viscous Properties and Microstructure of Recycled EVA Modified Bitumen," Fuel, Vol. 83, No. 1, 2004, pp. 31-38.

[22] Sung, Y. T., Kum, C. K., Lee, H. S., Kim, J. S., Yoon, H. G., and Kim, W. N., "Effects of Crystallinity and Crosslinking on the Thermal and Rheological Properties of Ethylene Vinyl Acetate Copolymer," Polymer, Vol. 46, No. 25, 2005, pp. 11844-11848.

[23] Heyes, D. M., Mitchell, P. J., and Visscher, P. B., "Viscoelasticity and Near-Newtonian Behaviour of Concentrated Dispersions by Brownian Dynamics Simulations," Trends in Colloid and Interface Science VIII Progress in Colloid \& Polymer Science, Vol. 97, Springer, New York, 1994, pp 179-182.

[24] Liu, Q., 2012, "Induction Healing of Porous Asphalt Concrete," Ph.D. thesis. TU Delft, The Netherlands. 